\title{
Twitter and Local Political Candidates in Japan: An Analysis of the 2011 Osaka Prefectural Assembly Election
}

\section{Introduction}

The Internet is an important and widely used tool for campaigning in many countries. A considerable number of studies have been conducted on the Internet's impact on elections. While many of the studies focus on Web 1.0 technology, such as websites and e-mail, this study focuses on social media, which is currently superseding Web 1.0 technology. Despite its growing importance in politics, few studies have examined the impact of social media sides such as Twitter or Facebook on elections, campaigns, or politics at large.

This paper investigates the factors affecting the use of social media, specifically Twitter, by political candidates at the local level in Japan. Most of the previous studies regarding the association of the Internet with elections in Japan have been conducted at a national level (Gibson and Ward 2003, 139). This study aims to address this deficit using the data from the 2011 Osaka Prefectural Assembly election. It has been demonstrated that some factors such as party affiliation, candidacy status, and electoral system, affect the likelihood of candidates to employ websites in their campaigns (Okamoto 2008). The key research question addressed in this study is whether these factors, cited above, also affect the usage of Twitter by candidates. The findings reveal that party affiliation is one of the determinants of Twitter usage by candidates; moreover, the electoral system has an impact on the usage although it apparently runs counter to the expectation drawn from previous studies on the effect of the electoral system on candidates' behavior.

\section{Internet in the Japanese Campaign Environment}

Before discussing the data analysis, Internet usage in the Japanese campaign environment is briefly reviewed. Despite Japan being one of the most Internetpenetrated countries among advanced democracies, the use of the Internet as 
a campaign tool is strictly restricted by the Public Office Election Law, which regulates campaign activities (Tkach-Kawasaki 2003). The law stipulates that candidates cannot give documents to the public, except for leaflets and pamphlets in limited numbers. Posting campaign information on the Web is considered to be same as giving documents to the public, which is prohibited. Furthermore, the law does not allow candidates to update their websites or send any electronic information during the campaign period (Okamoto 2011).

Nevertheless, many candidates set up websites and kept them up during the campaign period in recent years because candidates can maintain information on the Web that was posted before the start of the official campaign period; it is considered part of their "regular political activities", rather than "campaign activities". ${ }^{17}$ As shown in Figure 1, the rate of website establishment by candidates in national-level elections has been rising since the 2000 Lower House election, reaching almost $90 \%$ in recent elections. Therefore, we can conduct an empirical study on Internet usage in Japanese elections.

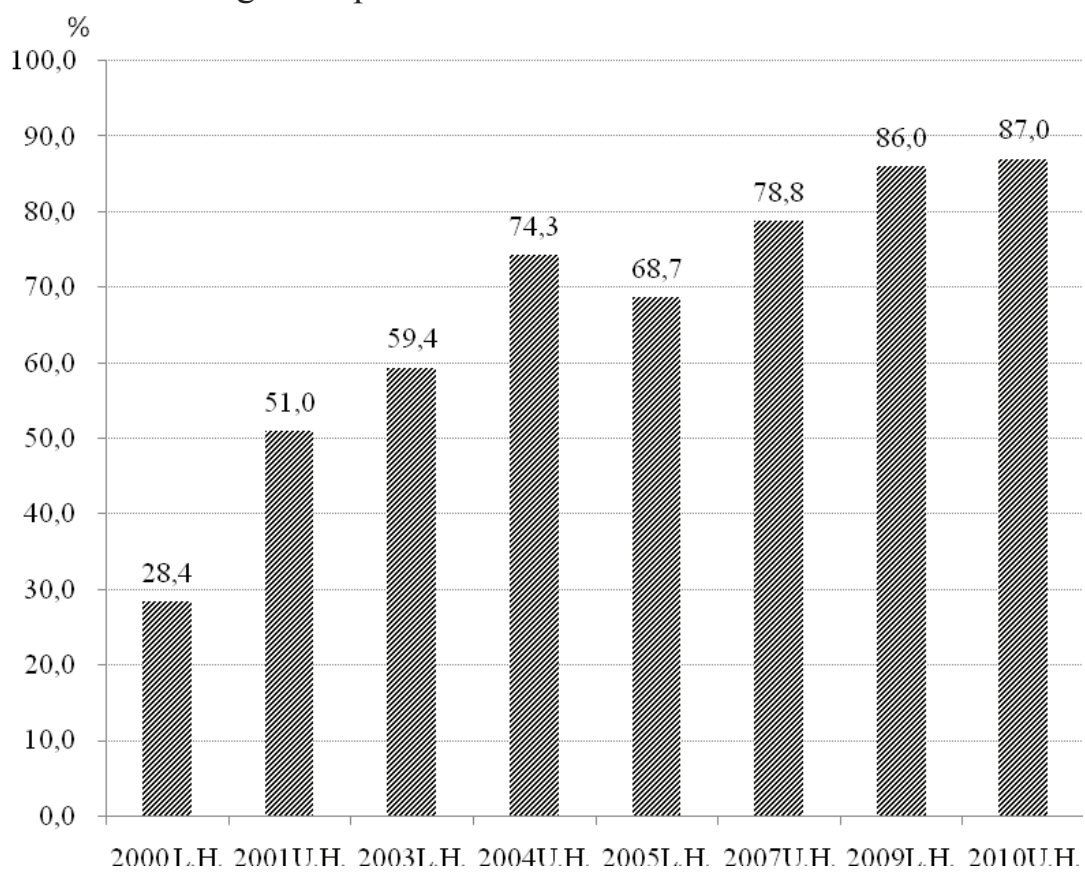

Figure 1. The Trend of Website Establishment Rate by Candidates

Note: „L.H.” and „U.H.” stand for the Lower House election, and the Upper House election, respectively.

17 The problem is that it is very difficult to distinguish "regular political activities" from "campaign activities". The Public Office Election Law does not stipulate the difference between regular political activities and campaign activities in clear terms. 


\subsection{Candidates' Use of the Internet in the 2011 Osaka Prefectural Election}

To investigate the use of Twitter by candidates, the author used the data from the Osaka Prefectural Assembly election conducted on April 10, 2011. Osaka is the third largest prefecture among the 47 prefectures in Japan, with a population of 8.8 million. The Osaka Prefectural Assembly is unicameral, with a Governor holding executive power, and it consists of 109 members, who are elected every four years. ${ }^{18}$

The data was obtained by determining the candidates that used Twitter in the Osaka Prefectural Assembly election, and by then examining each candidate individually between March 23 and April 1. It was found that 23.8\% (49 of 206) of the candidates used Twitter. Compared with the candidates' website usage, which was $74.8 \%$ (154 of 206), Twitter usage remained low partly because of its novelty. The results are not very different from that of the national-level election. Nakanishi (2011) reported that in the 2010 Upper House election in Japan, 30.4\% (133 of 438) of the candidates had a Twitter account, and 76.5\% (335 of 438) had a website presence (Naknishi 2011, Okamoto 2011). The findings from Japanese elections apparently counter those of Lynch and Rozell (2002) and Rackaway (2007), which suggest the existence of a lag between national and local candidates in adopting new campaign technologies.

\subsection{Bivariate Analysis of Twitter Adoption}

In this section, the simple relationship between Twitter usage by candidates and each of the following is examined: party affiliation, incumbency, electoral system, and socio-demographic factors.

\subsubsection{Party Affiliation}

Party affiliation might be an important factor for explaining candidates' Twitter usage (Karlsen 2011, 12). As shown in Figure 2, there are party differences of less than 1\% (Pearson's Chi Square test result value is 37.44) among candidates with regard to Twitter usage. The candidates of "Osaka Ishin no Kai" (The Osaka Restoration Association, hereafter referred to as Ishin) were the most probable users of Twitter. Ishin is a new local party created in 2010, headed by Toru Hashimoto the former governor of the Osaka Prefecture and the current mayor of Osaka City (2011). Due to the huge popularity of Hashimoto (a lawyer by profession who regularly appeared on television before taking office as governor) and the party's radical plan to reform the Japanese local system, which appealed to a broad electorate, Ishin won 57 of 109 seats in the 2011 election.

18 The number of members is scheduled to be reduced to 88 in the next election, conducted in 2015 . 


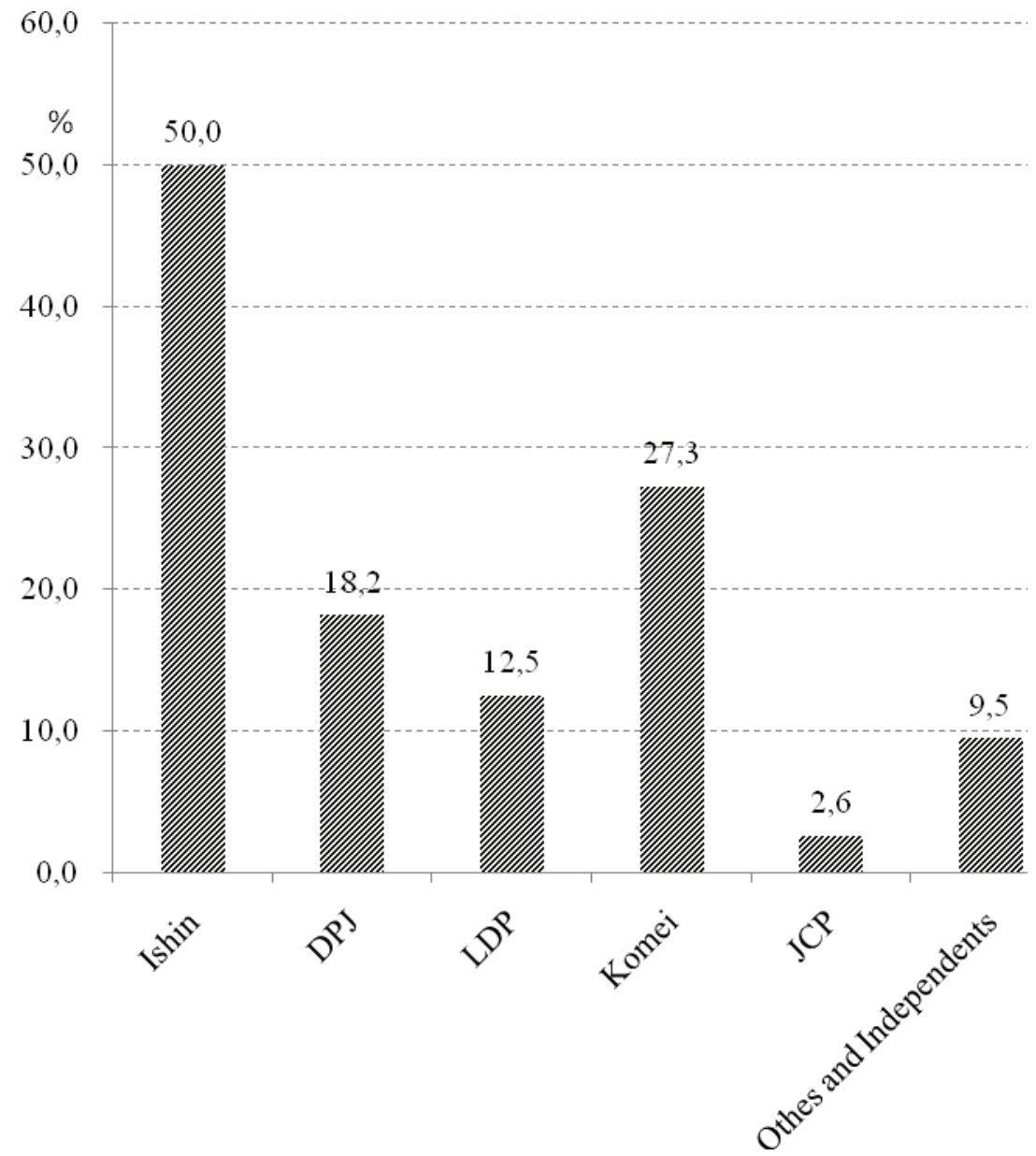

Figure 2. Twitter Adoption Rate by Political Party

Source: the Author own search query

Compared with the number of Ishin candidates who utilized Twitter, those in the Democratic Party of Japan (DPJ) and the Liberal Democratic Party (LDP) the two major parties fighting for power at a national level-were strikingly low, at less than $20 \%$. Although the share of the Komei Party, a coalition partner of LDP from 1999 to 2009, was relatively high, Twitter usage was still more than $20 \%$ points lower than that of the Ishin candidates.

At first glance, these results possibly support the "equalization" thesis on the impact of the Internet on politics. Because Internet facilitates dispatch information cheaper, the thesis predicts that the Internet could level the playing field among political candidates. Therefore, new parties or fringe candidates can exploit the nature of the medium to assert their presence alongside established parties 
or strong candidates (Okamoto 2008, 18). The findings that the newly formed Ishin outperformed established parties such as the DPJ, the LDP, and Komei in using of Twitter appears to support the equalization thesis.

However, we should note that many Ishin candidates were "party switchers" from the established parties. There were 24 of 60 candidates $(40 \%)$ who ran for the previous election in 2007 as LDP candidates, and 2 of the 60 ran as DPJ candidates. This suggests that the result demonstrated above may not support the equalization thesis but rather support the "normalization" thesis. Normalization claims that cyberspace reflects the real world in which politicians or candidates with abundant resources in terms of finance and staff are dominant over those with fewer resources. Additionally, party leaders might encourage their candidates to go online (Lassen and Brown 2010). Hashimoto - the Ishin leader-reportedly urged the local assembly members and candidates of his party to use Twitter and tweet frequently. However, a similar effort by other parties was not observed.

\subsubsection{Candidate's Status}

If the equalization thesis held true, challenger candidates would be more probable to utilize Twitter than incumbents because challengers generally have fewer financial and staff resources than that of incumbents; in addition, they have a stronger incentive to exploit Twitter to establish their presence in the campaign. In fact, the share of Twitter usage by challengers $(25.2 \%$; 36 of 143$)$ was higher than that of incumbents $(20.6 \% ; 13$ of 63$)$ although the difference is not significant even at a $10 \%$ level.

However, after dividing the incumbents into two groups by the number of times one has been elected to the Assembly, a 1-2 time elected group and a 3 or more times elected group, the results changed. The share of Twitter usage in the 1-2 times group (35.1\% or 20 of 57 ) was higher than that of challengers ( $22.8 \% 26$ of 114$)$, whereas that of the 3 or more times group was the lowest (8.6\% 3 of 35).

Some political scientists have provided evidence that normalization is in progress in some developed countries such as the U.S., the U.K., Germany, and Japan (e.g., Margolis, Resnick, and Wolfe 1999; Margolis, Resnick, and Levy 2003; Gibson, Rommel, and Ward 2003; Okamoto 2008). The previous studies that support the normalization thesis mainly focused on website usage. In addition, the results using Twitter data appear to support the normalization thesis.

\subsubsection{Electoral system}

By assuming that the ultimate goal of the candidates' Twitter usage is to increase the probability of being elected, Twitter can be considered as a tool for cultivating the candidates' personal reputations to maximize the vote share (Okamoto 2008, 18). It is important to mention that the strength of the candidates' personal incentives to cultivate reputations varies with the electoral rule (Cary and 
Shugart 1995); in this case the likelihood for the candidates to use Twitter will also be affected by the electoral rule.

Table 1. Cross-tabulation of SMD vs. SNTV and Twitter Adoption

\begin{tabular}{|c|c|c|c|c|}
\hline & & \multicolumn{2}{|c|}{ Electoral System } & \\
\hline & & SMD & SNTV & \\
\hline & Yes & 23 & 26 & \\
\hline Twitter Adoption & & $(28.8 \%)$ & $(20.6 \%)$ & \\
\hline & No & 57 & 100 & \\
\hline & & $(71.2 \%)$ & $(79.4 \%)$ & \\
\hline & Total & 80 & 126 & \\
\hline & & $(100 \%)$ & $(100 \%)$ & \\
\hline
\end{tabular}

Source: the Author own search query

The Osaka Prefectural Assembly is elected from 33 single-member districts (SMD), 21 double-member districts, three three-member, one four-member, three five-member, and one six-member district. In the multi-member districts, a single non-transferable vote (SNTV) system is employed. Therefore, the electoral system used in the Osaka assembly election is a mixed-member system that combines two electoral rules, the SMD and the SNTV, into a single election. Cary and Shugart (1995) argued that SNTV provides a stronger incentive to increase personal reputations than that by the SMD because under the SMD system, in which there is one candidate from one party in one district, candidates compete with each other under the party's banner rather than individually. From this argument, it is expected of SNTV candidates to use Twitter more than the SMD candidates. However, the results shown in Table 1 do not support this expectation. The proportion of candidates who use Twitter was greater among the SMD candidates than that among the SNTV candidates although the difference is insignificant even at a $10 \%$ level. One of the reasons the SNTV provides a strong incentive to increase personal reputation for candidates is that two or more candidates from the same party generally contest against each other in the same district. However, in the 2011 election there were only three cases (Higashi-Osaka district, Toyonaka district, and Hirakata district) that came under this type of district. Therefore, the effect of SNTV might have been hampered.

\subsubsection{Socio-Demographic Factors}

Familiarity with Information Communication Technology (ICT) is possible to influence a candidate's decision to use Twitter. While it is difficult to measure the candidates' familiarity, socio-demographic factors such as age and education 
are generally employed as its proxy. As young people typically tend to utilize ICT more than older people, we expect that a younger candidate is more probable to use Twitter. Lassen and Brown (2011) demonstrated that age had a strong and consistent effect on Twitter usage by U.S. Representatives. ${ }^{19}$

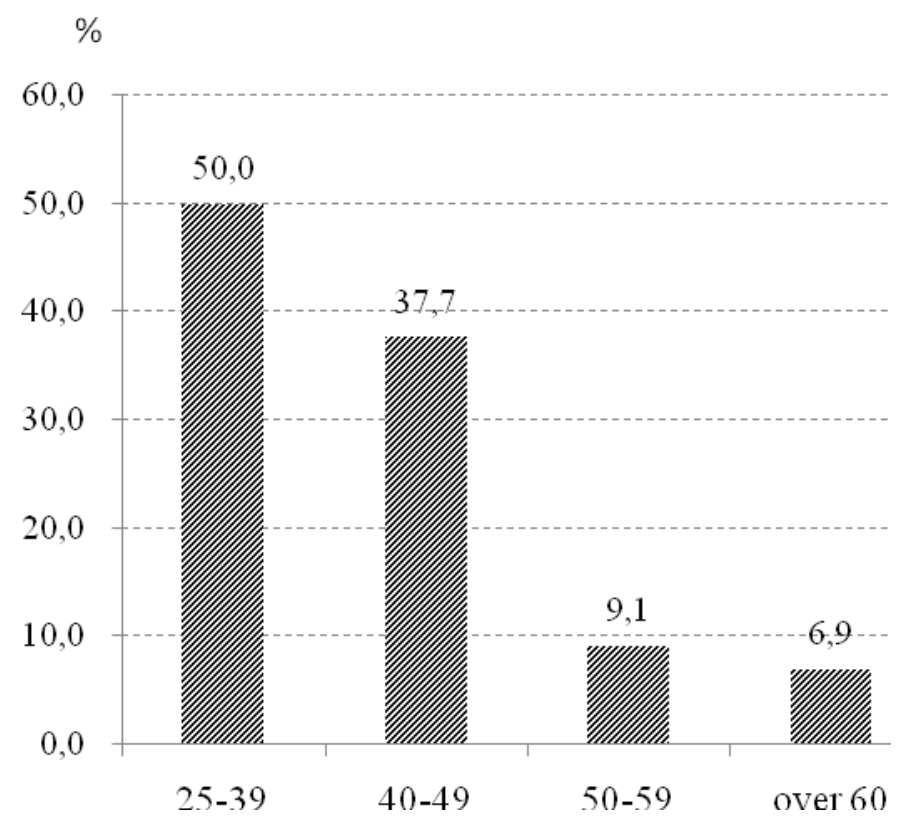

Figure 3. Twitter Adoption Rate by Age Group

Source: the Author own search query

The above expectation holds true. As shown in Figure 3, 50\% of candidates aged 25-39 and approximately $40 \%$ of the candidates aged $40-49$ had a Twitter account. In contrast, the proportion of candidates aged 50-59 and over 60 was less than $10 \%$. The difference among age groups is significant at a less than $1 \%$ level (Pearson's Chi Square test result value is 36.52).

Another factor of Twitter usage is the candidates' education level. It is expected that candidates with higher education are more probable to utilize Twitter. Table 2 appears to confirm this prediction. Approximately $27 \%$ of the candidates who graduated from college or higher used Twitter, whereas the proportion of all other candidates having a Twitter accounts is only $13 \%$. However, the difference between them is significant at a $10 \%$ (Pearson's Chi Square test result value is $3.77, p=.052)$.

19 However, Karlsen (2011) showed that candidates between the ages of 36-50 used Twitter more extensively than younger candidates by examining the data from the 2009 Norwegian campaign. 
Table 2. Cross-tabulation of Twitter Adoption and the Candidates' Level of Education

\begin{tabular}{|c|c|c|c|}
\hline & & \multicolumn{2}{|c|}{ Level of Education } \\
\hline & & $\begin{array}{c}\text { Graduated from College or } \\
\text { Above }\end{array}$ & Others \\
\hline & Yes & 43 & $(13.0 \%)$ \\
\hline Twitter Adoption & & $(26.9 \%)$ & 40 \\
\hline & No & 117 & $(87.0 \%)$ \\
\hline & & $(73.1 \%)$ & 46 \\
\hline & Total & 160 & $(100 \%)$ \\
\hline
\end{tabular}

Source: the Author own search query

\section{Multivariate Analysis}

Having found some relationship between Twitter usage and several factors by employing vicariate analyses, the relationship between them will be investigated in detail using multivariate analysis.

\subsection{Dependent and Independent variables}

The dependent variable, a candidate's usage of Twitter, is a dichotomous variable (coded 1 if a candidate had a Twitter account and 0 otherwise), and logistic regression analysis is used to estimate the effect of independent variables on the adoption of Twitter by the candidates. The independent variables were classified into five major categories: party affiliation, incumbency, electoral system, district characteristics, and the socio-economic status of the candidates.

Party affiliation variables consist of five dummy variables for DPJ, LDP, Komei, JCP, and independents/other candidates. In addition to these party variables, I include a variable depicting whether a candidate was a party switcher from major parties in the analysis. Approximately half of the Ishin candidates, as indicated above, were ex-LDP or ex-DPJ assemblymen. The former affiliation with the two major parties might affect the adoption of Twitter by the candidates. If this holds true, it would partially support the normalization thesis, in which candidates of major parties are more active in utilizing ICT than those of minor parties or independent candidates. The party-switcher variable is a dummy variable; it is coded 1 if a candidate has defected from DPJ or LDP to join the Ishin or 0 otherwise. The reference category here is the other non-switcher Ishin candidates.

The incumbency variable is a dummy variable; it is coded 1 if a candidate is an incumbent or 0 otherwise. To estimate the effect of the electoral system on 
Twitter usage, a dummy variable (coded 1 if a candidate ran in an SNTV district and 0 in an SMD district) is employed. Moreover, in order to estimate the effect of the electoral system more specifically, a dummy variable depicting a rivalry among candidates of the same party is included in the analysis (coded 1 if another candidate from the same party ran in the same district and 0 otherwise). This implies that the sign of the coefficient for both of these electoral system-related variables is expected to be positive.

Although not previously discussed, district characteristics would be important determinants for whether candidates utilize ICT as a campaign tool. The more voters in a district that have access to the Internet, the more probable candidates will be to use it as an effective campaign tool. Because there is no direct measure of the adoption rate by district level of the Osaka Prefectural election, the share of population in densely inhabited districts, which indicates a degree of urbanity, is utilized as the proxy for the degree of Internet adoption. There is a strong association between Internet penetration and urbanity (Adler, Gent, and Overmeyer 1998). This variable may have a positive effect on Twitter adoption.

In addition to the variables mentioned above, three socio-economic status variables are included in the analysis: age, education, and the gender of the candidates. Education is a dichotomous dummy variable that is coded 1 if a candidate graduated from college or higher; otherwise it is coded 0 if otherwise. Gender is also treated as a dichotomous variable, with 1 for male candidates and 0 for females. It cannot be predicted whether the coefficient of this gender variable is positive or negative. ${ }^{20}$

\subsection{Results: Determinants of Twitter Use}

In Table 3, the results of logistic regression are presented. Looking at the socioeconomic status variables, only the age variable is significant, at $p<.000$. As expected, the younger a candidate is, the more likely he or she is to use Twitter.

Regarding party variables, the DPJ- or the LDP-turned Ishin dummy and the Komei dummy have a significant effect on the adoption of Twitter. The coefficients of the two variables are shown to be positive. Because the reference category comprises non-switcher Ishin candidates, these results demonstrate that the Ishin candidates who were formerly affiliated with DPJ or LDP and the Komei candidates were more probable to use Twitter than non-switcher Ishin candidates. The difference in Twitter usage could be found among the candidates within the same party, i.e. the Ishin; the former affiliation with the two major parties,

20 Lassen and Brown (2010) demonstrated that the electoral marginality had a positive impact on Twitter usage by examining U.S. data. Although I tried to estimate its effect by using the data on the electoral competitiveness in the 2007 Osaka Prefectural Assembly election, a similar result could not be found (the details of which are not shown here). 
rather than the current affiliation with the newly rising party, affected the adoption of Twitter. The candidates of Komei, one of the major parties at the national level, were more probable to utilize Twitter than the non-switcher Ishins. These results partially support the normalization thesis as argued above. However, we should notice that a statistical difference could not be found between the LDP or the DPJ candidates and the Ishin candidates other than the former the DPJ or the LDP members.

Regarding incumbency, the dummy variable is not significant even at a $10 \%$ level, which does not support the normalization thesis. In contrast, the electoral system has a significant effect on Twitter usage; candidates who ran in an SNTV district were less probable to use Twitter than those in an SMD district. This result counters the expectation that SNTV candidates might be more active in using ICT, based on the assumption that SNTV provides a stronger incentive for candidates to increase personal reputations to maximize their vote share.

Table 3. Logistic Regression Result for Twitter Adoption

\begin{tabular}{|c|c|c|c|}
\hline Independent Variables & $\boldsymbol{\beta}$ & $\boldsymbol{p}$ & $\boldsymbol{E x p}(\boldsymbol{B})$ \\
\hline Party Affiliation (Non-Switcher -Ishin) & & & \\
\hline DPJ & -.072 & .921 & .931 \\
\hline LDP & -.884 & .229 & .413 \\
\hline Switcher to the Ishin from DPJ or LDP & 3.340 & .000 & 28.209 \\
\hline Komei & 1.884 & .028 & 6.580 \\
\hline JCP & -1.308 & .288 & .270 \\
\hline Ind. \& others & -.043 & .964 & .958 \\
\hline Incumbency (Challenger) & .817 & .241 & 2.265 \\
\hline SNTV (SMD) & -1.050 & .038 & .350 \\
\hline Rivalry within the Same District & -1.108 & .431 & .330 \\
\hline DID & 6.482 & .063 & 653.511 \\
\hline Age & -.174 & .000 & .840 \\
\hline Education (Below College Degree) & -1.313 & .064 & .269 \\
\hline Gender (female) & .460 & .576 & 1.584 \\
\hline Constant & 1.265 & .738 & 3.543 \\
\hline N & 206 & & \\
\hline Note: Reference categories in parentheses. & & & \\
\hline
\end{tabular}

Source: the Author own search query 


\section{Conclusion}

This study analysed the factors that impact the adoption of Twitter by political candidates. The findings obtained do not necessarily support the normalization thesis; the affiliation with major parties only had a limited impact on the usage of Twitter, and the dominance of incumbents does not affect Twitter usage.

It is premature to conclude that normalization is not progressing at a local level (unlike at the national level) in Japan, based solely on the results obtained in this study. The previous study focusing on the Web presence of the candidates in the 2000 Lower House election, in which the establishment rate of websites by the candidates was slightly more than $28 \%$, revealed a partial tendency toward normalization (Okamoto 2001). As stated earlier, normalization has been progressing rapidly since then, at least from the viewpoint of Web presence and website contents. Therefore, normalization might be accelerated further at the local level as Twitter will be more commonly used among candidates in the near future. Longitudinal research should be conducted to investigate whether normalization will progress even further at the local level as the Internet is constantly getting upgraded.

Additionally, a simple dummy variable was used for indicating whether candidates had a Twitter account; the drawback is that it does not consider how actively they used it. Thus, future research can explore the issues identified in this study by using a refined dependent variable to measure the extent to which candidates use Twitter aggressively.

\section{Reference}

Adler, E. Scott., Chariti E. Gent, and Cary B. Overmeyer. (1998). 'The Home Style Homepage: Legislator Use of the World Wide Web for Constituency Contact'. Legislative Studies Quarterly, 33: 585-95.

Carey, John M., and Matthew S. Shugart. (1995). 'Incentives to Cultivate a Personal Vote: a Rank Ordering of Electoral Formulas'. Electoral Studies 14: 417-39.

Gibson, Rachel., Stephen Ward, 'Letting the Daylight in Australian Parties' Use of the World Wide Web at the State and Territory Level. (2003). In Rachel Gibson, Paul Nixon, and Stephen Ward Political Parties and the Internet: Net Gain ?, London: Routledge: 139-160.

Karlsen, Rune (2011). 'A Platform for Individualized Campaigning? Social Media and Parliamentary Candidates in the 2009 Norwegian Election Campaign'. Policy \& Internet 3: 3-4.

Lassen, David. S, and Adam. R. Brown (2011). 'Twitter: The Electoral Connection?' Social Science Computer Review, 29: 419-36.

Lynch, G. Patrick, and Mark J. Rozell. (2002). “The „Congressionalization” of State Legislative Races'. The Social Science Journal 39: 43-51.

Ministry of Internal Affairs and Communication (2012). White Paper: Information and Communications in Japan. URL: <http://www.soumu.go.jp/johotsusintokei/whitepaper/eng/ WP2011/2011-index.html> [accessed December 12, 2012] 
Nakanishi, Goshi (2011).'Inta-netto (the Internet) wo riyo shita senkyo undo no yuko sei to aratana tohyo kodo no kano-sei: 2010 nen sangi-in senkyo ni okeru seito/kohosha no uebusaito (Website), tuitta (Twitter) nado no chosa wo chusin ni' (How the Internet is Transforming Election Campaign and Voting Behavior: Focusing on Candidates' Websites and Twitter in the Upper House Election of Japan). Master Dissertation, Tokyo: Rikkyo University.

Okamoto, Tetsukazu (2001). '2000 nen shuin sosenkyo ni okeru kohosha homu-peji (homepage) no bunseki' (A Study on the Use of Internet Homepage in the 2000 House of Representative Election). Leviathan 29: 141-154.

Okamoto, Tetsukazu. (2008). 'Use of Campaign Websites Based on Data from the 2003 Representatives election of Japan'. Nomos 22: 11-26.

Rackaway, Chapman. (2007). 'Trickle-down Technology? The Use of Computing and Network Technology in State Legislative Campaigns'. Social Science Computer Review 25: 466-83.

Tkach-Kawasaki, Leslie M. (2003). 'Politics@Japan: Party Competition on the Internet in Japan'. Party Politics 9: 105-23.

Vergeer, Maurice., Liesbeth Hermans, and Steven Sams (2011), 'Online Social Networks and Micro-blogging in Political Campaigning: The Exploration of a New Campaign Too and a New Campaign Style'. Party Politics: 1-25. 